\title{
A Capacitação na Consulta de Medicina Geral e Familiar: Como se Comporta ao Longo do Tempo Após a Última Consulta
}

\author{
Enablement in the General Practice Setting: How it Evolves After a \\ Medical Appointment
}

Filipe Vaz", Luiz Miguel Santiago**, Francisco Carvalho ${ }^{* * *}$

Pontos-chave:

Os utentes que não têm consulta há mais tempo estão aparentemente mais capacitados talvez pelo tempo de conhecimento do médico será importante.

É necessário que o médico reserve uma parte do seu tempo para esclarecer dúvidas e verificar se os consulentes compreendem aquilo que Ihes foi dito.

Cada utente é diferente e exige uma abordagem adaptada às suas necessidades.

\section{Resumo}

Introdução: É importante estudar em Medicina Geral e Familiar o ganho que os consulentes adquirem após contacto com o médico de família, avaliando-se alterações da capacitação após este contacto e diferenças consoante o tempo decorrido desde a última consulta. O estudo teve como base um instrumento validado para o efeito, o Instrumento de Capacitação do Consulente.

Metodologia: Este foi um estudo observacional, transversal, em que o Instrumento de Capacitação do Consulente foi aplicado oralmente a 290 utentes que aguardavam, na sala de espera do Centro de Saúde da Covilhã, por consulta médica. Registaram-se também os dados de cada paciente relativamente ao tempo decorrido desde a última consulta com o mesmo médico, idade, sexo, toma diária de medicamentos, grau de instrução, atividade profissional e se vivia, ou não, acompanhado(a).

Resultados: Em 5 das 6 questões, as respostas mais vezes registadas foram "igual ou pior" e "igual ou menos", com exceção da pergunta "capaz de se manter saudável”, em que os inquiridos responderam em igual número "melhor" e "igual ou pior". Invariavelmente, as respostas menos vezes assinaladas foram "muito meIhor" e "muito mais". Nas questões "capaz de compreender a sua doença” (58,5\% vs. 40,3\%; p=0,018), "capaz de lidar com a sua doença” (62,8\% vs. 45,2\%; p=0,044) e "capaz de se ajudar a si próprio" (52,5\% vs. 33,9\%; $p=0,028)$, os pacientes consultados há menos de 3 meses sentiam-se mais vezes "igual ou pior" ou "igual ou menos" comparativamente com os que haviam sido há mais de 6 meses.

Discussão e conclusão: O aumento da capacitação após consulta com o(a) médico(a) de família foi baixo de uma forma geral, apesar de mais marcado nos utentes que tinham tido pelo menos uma consulta nos últimos 3 meses, provavelmente devido a patologias crónicas. 0 Instrumento de Capacitação do Consulente está subaproveitado, sugerindo-se mais estudos para perceber melhor as alterações da capacitação na população portuguesa após uma consulta médica.

Palavras-chave: Cuidados de Saúde Primários, Medicina Geral e Familiar, Patient Enablement Instrument, Instrumento de Capacitação do Consulente, capacitação.

\footnotetext{
* Aluno do $6^{\circ}$ ano do curso de Medicina Mestrado Integrado na Faculdade de Ciências da Saúde da Universidade da Beira Interior

** MD, PhD, Assistente Graduado Sénior de Medicina Geral e Familiar, USF Topázio, ACeS Baixo Mondego e Professor na Faculdade de Ciências da Saúde da Universidade da Beira Interior

*** MD, Interno de Especialidade de Medicina Geral e Familiar, USF "A Ribeirinha"
} 


\section{Introdução}

Os CSP (Cuidados de Saúde Primários) são parte integrante do sistema de saúde de um país. Representam o primeiro contacto dos indivíduos, da família e da comunidade com o sistema nacional de saúde e devem situar-se o mais próximo possível do local onde as pessoas vivem e trabalham. A assistência à saúde é realizada de forma continuada e tem em atenção os problemas da comunidade, proporcionando serviços de promoção, prevenção, cura e reabilitação, conforme as necessidades ${ }^{1}$.

Ao longo dos últimos anos tem vindo a ser defendida, cada vez mais, uma abordagem centrada no paciente por parte dos médicos. Esta permite uma identificação de objetivos comuns entre médico e utente, com a partilha de decisões e responsabilidades. Existe uma evidência crescente de que a medicina centrada no doente estará associada a uma redução da utilização dos recursos de saúde ${ }^{2}$.

É relevante percebermos o ganho que os pacientes adquirem para a sua saúde, após a consulta com o(a) médico(a) de família; daí, ter vindo a ser dada uma importância crescente à capacitação do utente e à aliança estabelecida entre médico e paciente ${ }^{3}$. Neste sentido, o PEI (Patient Enablement Instrument) é um instrumento que permite analisar a capacitação do doente após uma consulta médica, tendo sido traduzido e validado para a língua portuguesa, com o nome de ICC (Instrumento de Capacitação do Consulente). Foi aplicado pela primeira vez em Portugal, em Coimbra, no ano de $2013^{4}$.

A presente investigação teve como objetivo dar continuidade ao primeiro estudo realizado em Portugal com o ICC, optando-se também por acrescentar uma nova abordagem, sobre a qual não foi encontrado qualquer estudo: verificar se existe uma alteração da capacitação do utente em função do tempo decorrido desde a última consulta com o(a) seu(sua) médico(a) de família.

\section{Metodologia}

Este foi um estudo observacional, transversal, que teve como base a aplicação do ICC a utentes do Centro de Saúde da Covilhã, que aguardavam na sala de espera por uma consulta com o(a) seu(sua) médico(a) de família. Como critérios de inclusão foram utilizados os seguintes parâmetros: cada paciente ter idade igual ou superior a 18 anos, ser capaz de responder ao inquérito na sua totalidade e já ter tido, pelo menos, uma consulta com o(a) atual médico(a) de família.
O ICC é composto por 6 perguntas destinadas a avaliar o resultado que o doente obtém para a sua saúde e vida em geral, em função de uma consulta com o(a) médico(a) de família. As questões são: "Capaz de lidar com a vida”, "Capaz de compreender a sua doença”, "Capaz de lidar com a sua doença", "Capaz de se manter saudável”, "Confiante em relação à sua saúde" e "Capaz de se ajudar a si próprio". Para as primeiras quatro perguntas, as respostas possíveis são: "muito melhor", "melhor" e "igual ou pior"; para as últimas duas: "muito mais", "mais" e "igual ou menos". Para além da aplicação do ICC, foi também registada relativamente a cada utente, a data da última consulta com o(a) médico(a) de família, a idade, o sexo, a toma diária de medicamentos, o grau de instrução, a atividade profissional e se vivia acompanhado(a).

O cálculo amostral para um nível de confiança de 95\% e uma margem de erro amostral de $5 \%$, foi realizado com base no número médio de consultas que se realizam no espaço de uma semana no Centro de Saúde da Covilhã.

Antes de se iniciar o trabalho, foi pedido um parecer à Comissão de Ética para a Saúde da ARS do Centro, bem como a aprovação do mesmo por parte do ACeS Cova da Beira.

Relativamente à análise estatística, o tratamento dos dados recolhidos foi feito com o auxílio do software "SPSS software for Windows - version 19.0" (SPSS Inc, Chicago, IL), sendo utilizada estatística descritiva e análise inferencial, após a verificação da normalidade dos dados. Foram realizados os testes não paramétricos Mann-Whitney U e Kruskal-Wallis, tendo-se definido como estatisticamente significativo o valor de $p<0,05$.

\section{Resultados}

Resultados gerais obtidos a partir da aplicação do ICC

Foi estudada uma amostra de $n=290$ utentes, sendo esta constituída por: $\mathrm{n}=183$ pessoas cuja última consulta com o(a) médico(a) de família havia sido há menos de 3 meses (63,1\%), $n=45$ entre 3 e 6 meses (15,5\%) e n=62 há mais de 6 meses (21,4\%). Dos utentes inquiridos, $n=175$ tinham menos de 65 anos (60,3\%) e $n=114$ eram do sexo masculino (39,3\%). Relativamente à TDM, $n=218$ pessoas $(75,2 \%)$ referiam fazê-lo. Quanto ao grau de instrução, baixo, médio e elevado, as respostas dadas foram $n=162$ (55,9\%), n=39 (13,4\%) e n=89 (30,7\%), respetivamente. No que concerne à atividade profissional, $n=105$ consulentes diziam encontrar-se ativos profissionalmente $(36,2 \%) ; n=40$ referiam morar sozinhos $(13,8 \%)$. 
Tabela 1: Caracterização da amostra total $(n=290)$

\begin{tabular}{|c|c|}
\hline Variável & $n(\%)$ \\
\hline \multicolumn{2}{|c|}{ Última consulta com o(a) médico(a) de família: } \\
\hline Há menos de 3 meses & $183(63,1)$ \\
\hline Entre 3 e 6 meses & $45(15,5)$ \\
\hline Há mais de 6 meses & $62(21,4)$ \\
\hline \multicolumn{2}{|l|}{ Grupo etário: } \\
\hline$<65$ anos & $175(60,3)$ \\
\hline$\geq 65$ anos & $115(39,7)$ \\
\hline \multicolumn{2}{|l|}{ Sexo: } \\
\hline Homem & $114(39,3)$ \\
\hline Mulher & $176(60,7)$ \\
\hline \multicolumn{2}{|c|}{ Toma diária de medicamentos: } \\
\hline $\operatorname{Sim}$ & $218(75,2)$ \\
\hline Não & $72(24,8)$ \\
\hline \multicolumn{2}{|l|}{ Grau de instrução: } \\
\hline Baixo & $162(55,9)$ \\
\hline Médio & $39(13,4)$ \\
\hline Alto & $89(30,7)$ \\
\hline \multicolumn{2}{|c|}{ Ativo(a) profissionalmente: } \\
\hline $\operatorname{Sim}$ & $105(36,2)$ \\
\hline Não & $185(63,8)$ \\
\hline \multicolumn{2}{|l|}{ Com quem vive: } \\
\hline Sozinho(a) & $40(13,8)$ \\
\hline Acompanhado(a) & $250(86,2)$ \\
\hline
\end{tabular}

As respostas globais obtidas na aplicação do ICC estão representadas na Tabela 2. Verificou-se que em 5 das 6 questões, as respostas mais vezes dadas foram "igual ou pior" e "igual ou menos". Isto ocorreu para as perguntas: "capaz de lidar com a vida" [n=176, $(60,7 \%)]$, "capaz de compreender a sua doença” [n=154, (53,1\%)], "capaz de lidar com a sua doença" [n=166, $(57,2 \%)]$, "confiante em relação à sua saúde" [n=168, (57,9\%)] e "capaz de se ajudar a si próprio" [n=132, (45,5\%)]. Na questão "capaz de se manter saudável”, os inquiridos responderam em igual número "igual ou pior" e "meIhor", [n=121, (41,7\%)]. De notar que, em todas as 6 perguntas, invariavelmente as respostas menos vezes assinaladas foram "muito melhor" e "muito mais".
Tabela 2: Respostas dadas pelos utentes às questões do ICC

\begin{tabular}{l|c|c|c} 
Questão & $\begin{array}{c}\text { Muito melhor } \\
n(\%)\end{array}$ & $\begin{array}{c}\text { Melhor } \\
n(\%)\end{array}$ & $\begin{array}{c}\text { Igual ou pior } \\
n(\%)\end{array}$ \\
$\begin{array}{l}\text { Capaz de lidar } \\
\text { com a vida }\end{array}$ & $28(9,7)$ & $86(29,7)$ & $121(41,7)$ \\
\hline $\begin{array}{l}\text { Capaz de } \\
\text { compreender a } \\
\text { sua doença }\end{array}$ & $35(12,1)$ & $101(34,8)$ & $154(53,1)$ \\
\hline $\begin{array}{l}\text { Capaz de lidar } \\
\text { com a sua doença }\end{array}$ & $31(10,7)$ & $93(32,1)$ & $166(57,2)$ \\
\hline $\begin{array}{l}\text { Capaz de se } \\
\text { manter saudável }\end{array}$ & $48(16,6)$ & $121(41,7)$ & $121(41,7)$ \\
\hline $\begin{array}{l}\text { Igual ou } \\
\text { relação à sua } \\
\text { saúde }\end{array}$ & 22(7,6) & $100(34,5)$ & $168(57,9)$ \\
\hline $\begin{array}{l}\text { Capaz de se } \\
\text { ajudar a si próprio }\end{array}$ & $41(14,1)$ & $117(40,3)$ & $132(45,5)$ \\
\hline
\end{tabular}

Resultados obtidos a partir da aplicação do ICC em função do tempo decorrido desde a última consulta com o(a) médico(a) de família

Na Tabela 3 encontram-se as respostas registadas em função do tempo decorrido desde a última consulta com o(a) médico(a) de família de cada um dos inquiridos. Para a pergunta "capaz de compreender a sua doença”, verificou-se que os indivíduos que tinham tido a última consulta há menos de 3 meses se sentiam mais vezes "igual ou pior", comparativamente com aqueles que tinham tido há mais de 6 meses $[n=107$ (58,5\%) há menos de 3 meses vs. $n=25$ (40,3\%) há mais de 6 meses, $p=0,018]$. Por outro lado, para a mesma questão, aqueles que tinham tido consulta há mais de 6 meses estavam mais vezes "muito meIhor" do que os que tinham tido há menos de 3 meses [n=12 (19,4\%) há mais de 6 meses vs. $n=17(9,3 \%)$ há menos de 3 meses, $p=0,018]$. Na pergunta "capaz de lidar com a sua doença", os utentes que tinham tido consulta há menos de 3 meses sentiam-se mais vezes "Igual ou pior" do que os que não tinham sido consultados nos últimos 6 meses [n=115 (62,8\%) há menos de 3 meses vs. $n=28$ (45,2\%) há mais de 6 meses, $p=0,044]$. Ainda relativamente à mesma questão, 
os que não tinham tido consulta nos últimos 6 meses com o(a) médico(a) de família responderam mais vezes "muito melhor" do que aqueles que tinham tido há menos de 3 meses [ $n=8(12,9 \%)$ há mais de 6 meses vs. $n=18(9,8 \%)$ há menos de 3 meses, $p=0,044]$. De igual forma, para a última pergunta do ICC, "capaz de se ajudar a si próprio", também os utentes que tinham tido consulta nos 3 meses mais recentes disseram, maioritariamente, sentir-se "igual ou menos" do que os que tinham sido consultados pela última vez há mais de 6 meses [n=96 (52,5\%) há menos de 3 me- ses vs. $n=21(33,9 \%)$ há mais de 6 meses, $p=0,028]$. Ainda na mesma questão, aqueles que não tinham estado presentes numa consulta nos últimos 6 meses disseram mais vezes sentir-se "muito mais" do que os utentes que tinham estado há menos de 3 meses [n=25 (13,7\%) há mais de 6 meses vs. $n=11(17,7 \%)$ há menos de 3 meses, $p=0,028]$.

Tabela 3: Respostas dadas pelos utentes às questões do ICC em função do tempo decorrido desde a última consulta com o(a) médico(a) de família

\begin{tabular}{|c|c|c|c|}
\hline \multirow[b]{2}{*}{ Questão } & \multicolumn{3}{|c|}{ Última consulta com o(a) médico(a) de família } \\
\hline & $\begin{array}{c}\text { Há menos de } 3 \text { meses } \\
\mathrm{n}(\%)\end{array}$ & $\begin{array}{c}\text { Entre } 3 \text { e } 6 \text { meses } \\
n(\%)\end{array}$ & $\begin{array}{c}\text { Há mais de } 6 \text { meses } \\
n(\%)\end{array}$ \\
\hline \multicolumn{4}{|c|}{ Capaz de lidar com a vida } \\
\hline Muito Melhor & $17(9,3)$ & $3(6,7)$ & $8(12,9)$ \\
\hline Melhor & $51(27,9)$ & $17(37,8)$ & $18(29,0)$ \\
\hline Igual ou pior & $115(62,8)$ & $25(55,6)$ & $36(58,1)$ \\
\hline \multicolumn{4}{|c|}{ Capaz de compreender a sua doença } \\
\hline Muito Melhor & $17(9,3)$ & $6(13,3)$ & $12(19,4)$ \\
\hline Melhor ${ }^{\mathrm{a}}$ & $59(32,2)$ & $17(37,8)$ & $25(40,3)$ \\
\hline Igual ou piora & $107(58,5)$ & $22(48,9)$ & $25(40,3)$ \\
\hline \multicolumn{4}{|c|}{ Capaz de lidar com a sua doença } \\
\hline Muito Melhor ${ }^{b}$ & $18(9,8)$ & $5(11,1)$ & $8(12,9)$ \\
\hline Melhor ${ }^{b}$ & $50(27,3)$ & $17(37,8)$ & $26(41,9)$ \\
\hline Igual ou piorb & $115(62,8)$ & $23(51,1)$ & $28(45,2)$ \\
\hline \multicolumn{4}{|c|}{ Capaz de se manter saudável } \\
\hline Muito Melhor & $30(16,4)$ & $6(13,3)$ & $12(19,4)$ \\
\hline Melhor & $69(37,7)$ & $22(48,9)$ & $30(48,4)$ \\
\hline Igual ou pior & $84(45,9)$ & $17(37,8)$ & $20(32,3)$ \\
\hline \multicolumn{4}{|c|}{ Confiante em relação à sua saúde } \\
\hline Muito Melhor & $13(7,1)$ & $3(6,7)$ & $6(9,7)$ \\
\hline Melhor & $58(31,7)$ & $21(46,7)$ & $21(33,9)$ \\
\hline Igual ou pior & $112(61,2)$ & $21(46,7)$ & $35(56,5)$ \\
\hline \multicolumn{4}{|c|}{ Capaz de se ajudar a si próprio } \\
\hline Muito Melhor ${ }^{c}$ & $25(13,7)$ & $5(11,1)$ & $11(17,7)$ \\
\hline Melhor $^{\mathrm{c}}$ & $62(33,9)$ & $25(55,6)$ & $30(48,4)$ \\
\hline Igual ou pior & $96(52,5)$ & $15(33,3)$ & $21(33,9)$ \\
\hline
\end{tabular}




\section{Discussão}

Um aspeto tido em conta neste trabalho, desenvolvido no Centro de Saúde da Covilhã, foi o de identificar o que é viável fazer para melhorar a qualidade do serviço prestado pelos médicos aos utentes, tendo em vista a sua saúde e bem-estar.

Relativamente à caracterização da amostra, é de notar que 183 utentes tinham tido pelo menos uma consulta nos 3 meses que antecederam a entrevista, o que representa $63,1 \%$ do total. Estes números são preocupantes, na medida em que parecem apontar para uma elevada percentagem de pessoas com doenças crónicas e/ou múltiplas patologias, que necessitam de visitar frequentemente o médico que as acompanha. Esta inferência ganha ainda mais força se virmos o número de pessoas que toma pelo menos um medicamento por dia, 218 (75,2\%). Destaque também para o facto de apenas 115 pacientes terem 65 ou mais anos, o que representa apenas $39,7 \%$ da amostra. Pode assim concluir-se que vários inquiridos com menos de 65 anos tomam medicamentos todos os dias e muitos deles tiveram necessidade de recorrer ao centro de saúde num espaço de tempo inferior a 3 meses.

Analisando os resultados deste estudo, concluímos que os utentes que não têm consulta há mais tempo estão aparentemente mais capacitados que aqueles que tiveram mais recentemente. Como interpretar estes dados? Possivelmente, devem-se ao diferente tipo de patologias apresentadas pelos doentes com consulta(s) nos últimos 3 meses comparativamente com os que tinham tido há mais tempo, uma vez que, provavelmente, muitos deles são consultados diversas vezes pelo seu(sua) médico(a) de família devido a doenças crónicas e/ou múltiplas patologias. Tendo em conta que o ICC é um questionário direcionado para as alterações que ocorrem na aprendizagem/capacitação, de acordo com uma consulta médica, sendo muitos dos utentes seguidos há já vários anos pelo(s) mesmo(s) motivo(s) e pelo(a) mesmo(a) médico(a), é mais difícil que existam diferenças, nomeadamente, no que respeita a lidar com a sua doença ou a percebê-la. Quem tem problemas de saúde crónicos é condicionado ainda, muitas vezes, por um grande sofrimento e debilidade, encarando a sua saúde de forma mais negativa, podendo a resposta dada apresentar uma perspetiva mais pessimista.

O que foi dito anteriormente, não invalida o papel fundamental do médico em relembrar aos seus pacientes, em cada consulta, a forma como devem lidar com os problemas, de forma a melhorarem a sua saúde em geral, indo ao encontro das suas expectativas. A ausência deste diálogo poderá acarretar uma diminuição da capacitação e piores resultados para a saúde de cada utente. Já os doentes que não são consultados há mais tempo serão porventura, aqueles que consultam o médico de forma mais esporádica, recorrendo ao centro de saúde sobretudo por uma questão de rotina ou devido a alguma patologia aguda. Neste último caso, desde que exista uma boa comunicação, será mais fácil para o médico ajudar o doente a lidar melhor com o seu problema e a compreendê-lo, o que trará benefícios também em relação à sua saúde em geral. Neste estudo não foi avaliada a patologia ou as patologias que os inquiridos apresentavam aquando da sua última consulta.

Um dos principais dados deste trabalho que merece ser salientado, relaciona-se com o elevado número de respostas "igual ou pior" e "igual ou menos". Fica a ideia da necessidade de o médico ter uma abordagem diferente ao longo consulta, sobretudo para com os pacientes cuja capacitação se prevê que apresente piores resultados após a consulta. É necessário que o profissional de saúde reserve uma parte do seu tempo para esclarecer dúvidas e verificar se os consulentes compreendem aquilo que Ihes é dito, podendo implicar uma melhor gestão do tempo, apesar de conhecidas as condicionantes atuais, como o tempo médio por consulta (5). Certos utentes necessitam que o médico invista uma parte mais significativa do seu tempo com eles, pois o nível de informação que o doente adquirirá ao longo da consulta estará relacionado com os seus níveis de confiança e potencial para enfrentar a(s) sua(s) doença(s). Apesar de tudo, realça-se a necessidade de uma abordagem holística perante todos os pacientes.

\section{Conclusões}

O principal objetivo deste estudo foi alcançado. Ele consistia em perceber se existiam diferenças na capacitação dos consulentes de acordo com o tempo decorrido desde a última consulta com o(a) médico(a) de família. Ao longo do estudo parece ter ficado evidente que o processo de capacitação obriga cada médico a dar o seu melhor do ponto de vista das competências comunicacionais. Cada utente é diferente e exige uma abordagem adaptada às suas necessidades. 0 caminho a seguir poderá passar por uma formação específica, contínua, que deve começar ainda no ensino pré-graduado. Tudo isto faz parte de um processo que obrigará a uma evolução dos médicos quer do ponto de vista técnico quer do ponto de vista humano (24). 


\section{Agradecimentos}

Agradece-se a todas as pessoas que participaram de forma anónima e desinteressada neste estudo.

A todos os que colaboram com o ACeS Cova da Beira e em especial ao seu Diretor Executivo, o Dr. João Bento, pela ajuda e disponibilidade prestadas.

A todos os que trabalham no Centro de Saúde da Covilhã e prestaram apoio na realização do trabalho.

\section{Referências Bibliográficas}

1. Declaration of Alma-ata. International Conference on Primary Health Care; 12 September 1978; Alma-Ata, USSR.

2. Pires P. Medicina centrada no paciente: melhor qualidade com menores custos. Revista Portuguesa de Clínica Geral. 2011;27(5):482-6.

3. Hudon C, Tribble DS-C, Bravo G, Hogg W, Lambert M, Poitras M-E. Family physician enabling attitudes: a qualitative study of patient perceptions. BMC family practice. 2013;14(1):8.

\section{Conflito de Interesses}

Os autores declaram não ter conflito de interesses relativamente a este artigo.

Endereço para Correspondência:

Filipe Vaz

Telemóvel: 938685876

Email: filipealvesvaz90@gmail.com

\section{Pontos-chave:}

- Aplicação do Instrumento de Capacitação do Consulente no Centro de Saúde da Covilhã;

- Que diferenças existem ao nível da capacitação entre utentes que consultaram o seu médico de família nos últimos 3 meses e aqueles que não o fazem há mais tempo;

- De que forma o médico pode aumentar a capacitação dos seus consulentes.

4. Pintalhão I, Santiago L. Validação da versão Portuguesa do Patient Enablement Instrument e sua aplicação em Medicina Geral e Familiar [Master's thesis]: Faculdade de Medicina da Universidade de Coimbra; 2013.

5. Simões J. Ética das Pequenas Coisas. Revista ADSO.2:8-14.

6. Botas P. Capacitação: Uma Ciência com Arte. Revista ADS0.1:13-6. 